\section{Accidental human vaccination with vaccinia virus expressing nucleoprotein gene}

SIR-Infectious vaccinia virus recombinants that express genes of other pathogenic agents have been proposed as candidates for live vaccines ${ }^{1-9}$. In several cases, vaccination has been shown to effectively immunize and protect experimental or domesticated animals against a virus challenge. Here we report the physical and immunological responses in a human accidentally vaccinated while vaccinating mice with a recombinant, derived from the WR laboratory strain of vaccinia virus, which expresses the vesicular stomatitis protein $^{8}$. In this incident, the vaccinated human and experimental mice had the same specific antibody response.

Vesicular stomatitis virus (VSV) is an RNA-containing, bullet-shaped, enveloped rhabdovirus that causes a highly contagious vesicular disease of cattle, horses and pigs. In humans, vesicular stomatitis (VS) causes influenza-like symptoms ${ }^{10}$. Epizootics of VS in US cattle occurred in 1916, 1949, 1963, 1982 and 1985. Because VS is initially indistinguishable from footand-mouth disease, herds with VS must be quarantined at great cost to the livestock industry.

We are investigating the immunogenicity of infectious vaccinia virus recombinants that express the $\mathrm{G}$ and $\mathrm{N}$ proteins of vesicular stomatitis virus (VSV) ${ }^{8,11}$. While one of us (L.J.) was injecting mice with an infectious vaccinia virus recombinant expressing the N gene of VSV (v38), a small cut on the right ring finger was inoculated with a drop of virus $\left(3.0 \times 10^{6} \mathrm{PFU} / 0.05\right.$ $\mathrm{ml})$. Although L.J.'s hands were washed the mice. demonstrated $^{12}$ virus serotype Indiana (VSV-IND) $\mathrm{N}$

immediately, the finger was slightly reddened and swollen 4 days later, as were similar lesions on the vaccinated mice. The swelling progressed from the base of the fingernail past the first joint of the finger, restricting movement of the joint. On day 8 , the right axillary lymph node became swollen; the lymph node and finger swelling began to subside approximately 12 hours later. On day 10 , the finger swelling had completely disappeared, but a single localized pock lesion appeared in the reddened area, coinciding with the appearance of similar lesions in the mice. The lymph node swelling disappeared by day 12 . The lesions were completely healed by day 25 in both L.J. and

During the infection, L.J. did not experience fever or general malaise. The mildness of the infection is notable, despite the fact that a non-vaccine strain (WR) was involved in this exposure. The mildness of the infection could be related to a smallpox vaccination that L.J. had been given some 30 years before the accident, or to the attenuation of the vaccinia virus recombinant by the insertional inactivation of the thymidine kinase gene, as recently

Sera from L.J. and the mice were evaluated by immunoprecipitation of ${ }^{35} \mathrm{~S}$ methionine-labelled extracts of baby hamster kidney-21 cells infected with either VSV-IND or the VSV serotype New Jersey (VSV-NJ) and analysed on SDS-PAGE. There was only specific binding to the $\mathrm{N}$ protein of VSV-IND (Fig. 1). All sera were positive by ELISA

Fig. 1 An autoradiogram of SDS-PAGE analysis of sera from L.J. and vaccinated mice. The sera were immunoprecipitated as described by Kessler ${ }^{13}$ with a lysate of ${ }^{35} \mathrm{~S}$-methioninelabelled cells infected with either VSV-IND or VSV-NJ with an MOI of 4. SDS-PAGE ${ }^{14}$ was performed using a $10 \%$ acrylamide running gel, fixed, dried, and allowed to expose X-OMAT film for 2 days. Antigens: lanes $1-4,6,7$, and 10-15, VSV-IND; lanes 8 and 9, VSV-NJ. Sera: lane 1, from a mouse bearing a myeloma (P3X63) for fusion; lane 2, normal BALB/c mouse; lane 3, mouse anti-VSV-IND; lane 4 is mouse anti-VSV-NJ; lane 6 , mouse anti-v50 (a vaccinia recombinant bearing the gene for the VSV-NJ G protein); lanes 7 and 8 , normal human;

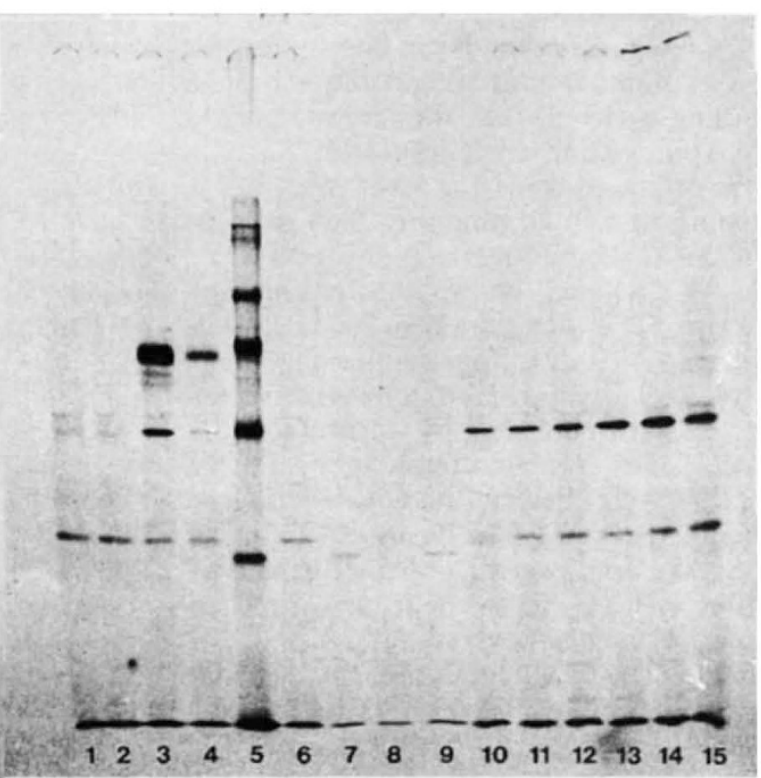
lanes 9 and 10, from L.J.; lanes 11-15, from five different BALB-c mice infected with v38. Lane 5 contains ${ }^{14} \mathrm{C}$ relative molecular mass standards $(200 \mathrm{~K}$ myosin, $100 \mathrm{~K} / 92.5 \mathrm{~K}$ phosphorylase $b, 69 \mathrm{~K}$ bovine serum albumin, $46 \mathrm{~K}$ ovalbumin, $30 \mathrm{~K}$ carbonic anhydrase, $14.3 \mathrm{~K}$ lysozyme). against whole VSV-IND and negative against whole VSV-NJ. The absence of binding to the G protein of VSV-IND indicated that L.J. had not been infected with VSV. As expected, the sera did not have serum-neutralizing antibodies for VSV-IND or VSV-NJ since the $\mathrm{N}$ protein does not cause the production of serumneutralizing antibodies. The neutralization titres to vaccinia virus of serum taken from L.J. 1 month and 4 months postinfection were 256 and 64 respectively, indicating that this was a recent infection.

These data demonstrate that the vaccinia virus recombinant can produce specific antibody to a non-vaccinia virus protein in humans as well as in mice.

\section{JONES* \\ S. Ristow' \\ T. YiLMA* \\ B. Moss $\ddagger$}

* Department of Veterinary Microbiology and Pathology,

Washington State University,

Pullman, Washington 99164, USA

$+U S D A-A R S$,

Pullman, Washington 99164, USA

$\mp$ Laboratory of Viral Diseases,

National Institutes of Allergy and

Infectious Diseases,

National Institutes of Health,

Bethesda, Maryland 20205, USA

1. Smith, G.L., Mackett, M. \& Moss, B. Nature 302, 490-495 (1983)

2. Paoletti, E. Lipinskas, B.R., Samsonoff, C. . Mercer, S. \& Panicali, D. Proc. natn. Acad. Sci. U.S.A. 81, 193-197 (1984)

3. Panicali, D., Davis, S.W., Weinberg, R.L. \& Paoletti, E. Proc. natn. Acad. Sci. U.S.A. 80, 5364-5368 (1983).

4. Smith, G.L., Murphy, B.R. \& Moss, B. Proc. natn. Acad. Sci. U.S.A. 80, 7155-7159 (1983)

5. Kieny, M.P. et al. Nature 312, 163-165 (1984)

6. Wiktor, T.F. et al. Proc natn. Acad. Sci. U.S.A. 81, 7194-7198 (1984)

Smith, G.L., Godson, B.N., Nussenzweig, V., Nussenzweig, R.S. \& Moss, B. Science 224, 397-399 (1984).

8. Mackett, M., Yilma, T., Rose, J.K. \& Moss, B. Science 227, 433-435 (1985)

9. Cremer, K.J., Mackett, M., Wohlenberg, C., Notkins, A.L. \& Moss, B. Science 228, 737.740 (1985)

10. Patterson, W.C., Mott, L.O. \& Jenney, E.W. J. Am. vet. med. Ass. 133, 57-62 (1958)

11. Yilma, T., Mackett, M., Rose, J.K. \& Moss, B. in Vaccinia Viruses as Vectors for Vaccine Antigens (ed. Quinnan, G.V. Jr) 187-200 (Elsevier, New York, 1985).

12. Buller, R.M., Smith, G.L., Moss. B., Cremer, K. \& Notkins, A.L in Vaccine 85 (eds Lerner, R.A. Chanock, R.M. \& Brown, F.) 175-176 (Cold Spring Harbor, New York. 1985).

13. Kessler, S.W. J. Immun. 115, 1617-1624 (1975).

14. Laemmeli, U.K. Nature 227, 680-685 (1970)

\section{Malaria - mitogens or super antigens?}

SIR-The induction of a variety of immune responses by malarial infections led Greenwood' and Wyler ${ }^{2}$ to propose the existence of a malaria mitogen. The activity of extracts of blood cells infected with Plasmodium falciparum and Plasmodium berghe $i$ has been studied using blast transformation of human peripheral blood lymphocytes $^{3-8}$ and rodent splenocytes ${ }^{9-11}$. The results ranged from the demonstra- 